\title{
for materials research...
}

\section{Low-Density Silicon Sponge Material:} Bisco Products' HT-3800 series are composite variations of silicone sponge reinforced with a double internal layer of fiberglass for greater dimensional stability. Applications include use as a seal in high-intensity discharge lamps in which the reinforcement ensures a seal that cannot be overtensioned. The products are resistant to compression set and are available in three grades: continuous-length 36-in.-wide (91.4 $\mathrm{cm}$ ) rolls, slit widths, or small-width tapes. Circle No. 61 on Reader Service Card.

Corrosion Reference Materials: Free 1996 product guide from NACE International offers more than 1,000 reference books, technical standards, software, and other products for use in corrosion control. The guide also includes conference papers, educational videos, and reports.

Circle No. 64 on Reader Service Card.

Rotational Viscometer: Haake's VT-550 measures the viscosity and flow behavior of liquid and semi-solid test materials. A controlled deformation test mode provides a reproducible means of measuring yield point, facilitated by a special vane sensor to preserve a material's structure during loading. Test programs can be stored on the instrument's internal memory, enabling users to automatically perform tests such as flow curves and viscosity/ time curves without a PC.

Circle No. 70 on Reader Service Card.

Ozone Detector Probe: The IL SED185 series probe from International Light measures light transmission in the 160-240 nm range for monitoring lamp degradation and the performance of ozone generators. Performing measurements in real time, the probe can be handheld or machine-mounted. Compatible with the IL1400A and IL1700 radiometers, the probe operates from $3 \times 10^{-8}$ to $4 \times 10^{-2} \mathrm{~W} / \mathrm{cm}^{2}$ and provides readouts in absolute units.

Circle No. 69 on Reader Service Card.

Closed Loop Actuators: Newport's $850 \mathrm{~F}$ precision linear actuators feature a compact envelope because the motor and spindle are placed side by side rather than end to end. The actuators offer $0.5 \mu \mathrm{m}$ bidirectional repeatability and minimum incremental motion. Consistent $0.1 \mu \mathrm{m}$ magnetic encoder resolution completes motion commands regardless of load, speed, or acceleration. A nonrotating tip eliminates torque on the drive components during motion reversal. The actuators provide a $50-\mathrm{mm}$ maximum travel range and moveable hard stops.

Circle No. 65 on Reader Service Card.

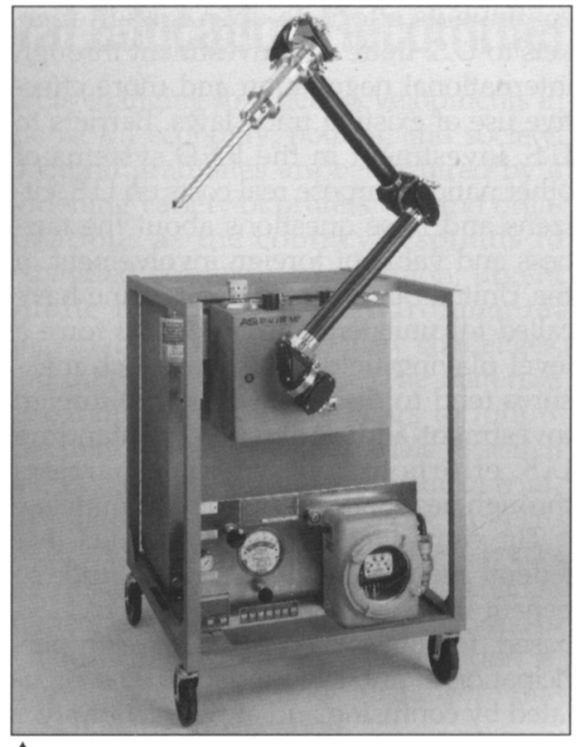

$\Delta$ FTIR Monitoring System for Latex Microemulsion Polymerization: ReactIR ${ }^{\mathrm{TM}}$ systems from ASI Applied Systems are designed for control of latex microemulsion polymerization reactions during development and synthesis of polymer products. The systems provide real-time data on reaction kinetics, concentration of critical reaction species, percent conversion, and reaction pathways. Latex product characteristics can be tailored to specific applications, and residual monomer concentrations can be determined.

Circle No. 63 on Reader Service Card.

\section{Chemical Resistance and Corrosion}

Databank: William Andrew Inc. offers a corrosion databank for metals, plastics, rubber, ceramics, and other materials. Included are textual, tabular, graphic, and image data. Three datasets are available: ASM International's Handbook of Corrosion Data for metals, Plastics Design Library's Chemical Resistance Databank for plastics and rubber, and a National Center for Manufacturing Sciences databank for data on the effects of cleaning solutions on materials used in manufacturing electronic parts.

Circle No. 66 on Reader Service Card.

Magnetic Sampler Temperature Control System: Walker Scientific's TCSC-1 enables users to test magnetic properties at temperatures ranging from -100 to $300^{\circ} \mathrm{C}$ with $\pm 1^{\circ} \mathrm{C}$ accuracy. The self-contained system features dial selectable temperature settings and consists of a temperature control chamber, coil set probe, power supply, and an electronic controller. The system can be customized for temperature range and sample size. Chamber and probe sizes for samples $1 \mathrm{~cm}^{2}$ and larger can be provided. Circle No. 67 on Reader Service Card.
TOF-SIMS System: Physical Electronics' TRIFT $^{\text {TM }}$ II system is a surface analysis technique used to mass analyze and image complex chemical species such as semiconductor devices, polymers, and biomaterials. The mass analyzer is an energy-compensating TOF mass spectrometer using three spherical electrostatic analyzers. Secondary ions are accelerated into the spectrometer where they are mass analyzed by measuring their TOF from the sample surface to the detector. The location of the species on the surface is also determined with submicrometer spatial resolution.

Circle No. 68 on Reader Service Card.

Polymer-Coated Alumina Columns: Gammabond $^{\text {Th }}$ columns from ES Industries are alumina-based HPLC columns designed for extreme $\mathrm{pH}$ applications. The columns can be used with buffer systems from $\mathrm{pH} 1.3$ to 12. They are stable to phosphate buffers, ion-pair reagents, and other mobile phase additives. The columns are available in four reversed phases: a low-load polybutadienecoated alumina for normal applications, a higher load polybutadiene for difficult separations, an alumina-based polysiloxane polymer to which n-octyl groups are appended, and alumina coated with octadecylpolysiloxane.

Circle No. 62 on Reader Service Card.

\section{Dissolution Testing and Automatic}

\section{Sampling Systems: Distek offers two} complementary systems to reduce operator time and effort for dissolution testing. The 2100 A test system features an obstructionfree vessel layout; automatic and vessel alignment; built-in paddle or basket height adjustment procedure; and a water bath design to eliminate leaks. The 2230A sampler can sample up to 12 vessels in the same footprint as that required for six vessels. Six pump channels can be calibrated simultaneously for accurate volume transfer. Up to seven dissolution protocols can be stored in memory. Circle No. 60 on Reader Service Card.

Benchtop Bonding Press: The Model K high-temperature bonding press from GL Applied Research is designed for bonding materials with surface areas up to 48 in. ${ }^{2}(1.2$ $\mathrm{m})$ and provides bonding forces and temperatures up to $5000\left(2760^{\circ} \mathrm{C}\right)$ and $750^{\circ} \mathrm{F}\left(400^{\circ} \mathrm{C}\right)$, respectively. Users program all operational parameters, including temperature setpoint, force, and ramp/soak profiles. Each of nine user-defined bonding profiles can incorporate up to nine temperature setpoints with a soak time of 0-999 minutes at each setpoint. Force and temperature are maintained with stability of $\leq 0.2^{\circ} \%$ of full scale and $\pm 5^{\circ} \mathrm{F}\left(2.8^{\circ} \mathrm{C}\right)$ of temperature setpoint, respectively.

Circle No. 71 on Reader Service Card. 